\title{
DESAIN JARINGAN WIRELESS MENGGUNAKAN DISTRIBUTION SYSTEM (WDS) DAN PENGUJIAN BERDASARKAN QUALITY OF SERVICE (QOS)
}

\author{
Muchamad Rusdan ${ }^{1}$, Muhamad Sabar ${ }^{2}$ \\ Informatika ${ }^{1,2}$ \\ Sekolah Tinggi Teknologi Bandung \\ Jalan Soekarno-Hatta No.378, Kota Bandung 40235 \\ rusdan@sttbandung.ac.id ${ }^{1}$, sabar@ $@$ sttbandung.ac.id $^{2}$
}

\begin{abstract}
Abstrak
Tujuan dari penelitian ini adalah merancang jaringan wireless yang memanfaatkan jalur wireless sebagai backbone pada semua access point kecuali basestation point yang tetap mempergunakan kabel UTP sebagai backbone-nya dan memperluas area jangkauan jaringan wireless yang mampu mencakup seluruh bagian di Universitas Widyatama. Hasil desain jaringan wireless dengan WDS akan diuji dengan melakukan simulasi. Kemudian pengujian akan difokuskan pada parameter delay, packet loss, throughput, dan jitter dengan menggunakan metode Quality of Service (QoS) menggunakan aplikasi Axence netTools. Desain jaringan wireless dengan Wireless Distribution System (WDS) memiliki tingkat fleksibilitas yang lebih baik daripada backbone yang menggunakan kabel Unshielded Twisted Pair (UTP). Hasil pengujian menunjukkan bahwa throughput, delay, packet loss, dan jitter menunjukkan hasil yang bagus. Hasil pengujian throughput didapatkan nilai rata-rata throughput dengan presentase sebesar 90\%, dapat dikategorikan BAGUS dengan indeks 3, sedangkan hasil pengujian delay didapatkan nilai ratarata sebesar107,8 dapat dikategorikan SANGAT BAGUS dengan indeks 4, kemudian nilai rata-rata packet loss dengan presentase 2\%, dapat dikategorikan BAGUS dengan indeks 3, dan hasil pengujian jitter diperoleh nilai yang bervariasi dengan nilai rata-rata jitter sebesar $1,71 \mathrm{~ms}$, dapat dikategorikan BAGUS dengan indeks 3.

Kata kunci : Wireless Distribution System, Quality of Service, Jaringan Wireless, Access Point, Unshielded Twisted Pair.
\end{abstract}

\begin{abstract}
The purpose of this research is to design a wireless network that utilizes wireless lines as a backbone on all access points except the base station point that still uses UTP cable as its backbone and expands the coverage area of wireless networks that are able to cover all parts of Widyatama University. The results of wireless network design with WDS will be tested by simulating. Then testing will be focused on parameters of delay, packet loss, throughput, and jitter using the Quality of Service (QoS) method using the Axis netTools application. Wireless network design with Wireless Distribution System (WDS) has a better level of flexibility than a backbone that uses Unshielded Twisted Pair (UTP) cable. The test results show that throughput, delay, packet loss, and jitter show good results. Throughput test results obtained an average value of throughput with a percentage of $90 \%$, can be categorized GOOD with index 3, while the delay test results obtained an average value of 107.8 can be categorized VERY GOOD with index 4, then the average value of packet loss with a percentage of $2 \%$, can be categorized GOOD with index 3, and the results of the jitter test obtained varying values with an average value of jitter of 1.71 $m s$, can be categorized GOOD with index 3.
\end{abstract}

Keywords: Wireless Distribution System, Quality of Service, Wireless Networks, Access Points, Unshielded Twisted Pair. 


\section{Pendahuluan}

Jaringan wireless dengan sangat pesat menjadi standar layanan yang diberikan pada sebuah organisasi institusi pendidikan maupun perusahaan. Ada banyak alasan jaringan wireless dapat berkembang dengan pesat, namun sebagian besar beralasan karena lebih murah dan lebih mudah didalam pemeliharaan dan pengembangan. Masalah muncul ketika area cakupan besar yang menyebabkan tidak dapat tertutupi seluruh area dengan satu perangkat wireless. Kondisi tersebut tentu saja membutuhkan pengaturan repeater yang sesuai dari perangkat wireless basestation point atau backbone. Masalah yang dihadapi dapat diselesaikan dengan menggunakan sistem Wireless Distribution System (WDS) melalui penempatan beberapa perangkat wireless pada mode bridge, tetapi tanpa perlu koneksi kabel Unshielded Twisted Pair (UTP) di antara perangkat. WDS merupakan salah satu sistem untuk mengembangkan jaringan wireless tanpa harus menggunakan kabel UTP sebagai backbone dari access point melainkan memanfaatkan jalur wireless dari access point tersebut (Zubairu, 2016).

Universitas Widyatama merupakan salah satu institusi perguruan tinggi swasta di Kota Bandung, yang menjadikan jaringan wireless sebagai salah satu fasilitas standar yang diberikan kepada mahasiswa, dosen, dan karyawan yang dapat diakses melalui perangkat mobile yang mendukung jaringan wireless (Rusdan \& Sabar, 2019). Fasilitas tersebut banyak membantu mahasiswa dan dosen dalam proses perkuliahan dan pencarian referensi untuk kepentingan perkuliahan. Jaringan wireless yang ada di Universitas Widyatama masih mempergunakan kabel UTP sebagai backbone dari access point. Penggunaan kabel UTP sebagai backbone dari access point menjadi salah satu kendala yang dihadapi, mengingat kampus Universitas Widyatama yang memiliki luas \pm 5 hektar, dengan backbone yang menggunakan kabel UTP memiliki keterbatasan jarak, semakin jauh jarak yang ditempuh maka semakin banyak kabel UTP yang harus digunakan dan akan sangat berpengaruh pada kualitas pengiriman dan penerimaan arus data. Maka dengan adanya permasalahan tersebut perlu dikembangkan jaringan wireless tanpa menggunakan kabel UTP sebagai backbone dari access point melainkan memanfaatkan jalur wireless dari access point yang disebut Wireless Distribution System (WDS) sebagai backbone dari access point.
Hasil desain jaringan wireless dengan WDS akan diuji dengan melakukan simulasi. Kemudian pengujian akan difokuskan pada parameter delay, packet loss, throughput, dan jitter dengan menggunakan metode Quality of Service (QoS) menggunakan aplikasi Axence netTools (Rusdan, 2019).

Tujuan dari penelitian ini adalah merancang jaringan wireless yang memanfaatkan jalur wireless sebagai backbone pada semua access point kecuali basestation point yang tetap mempergunakan kabel UTP sebagai backbone-nya dan memperluas area jangkauan jaringan wireless yang mampu mencakup seluruh bagian di Universitas Widyatama.

\section{KAJIAN LITERATUR}

Pada penelitian Dalam tulisan Zubairu (2013), Wireless Distribution System Network (WDSN) telah dikembangkan menggunakan Wireless Distribution System (WDS), WDSN dirancang dan disimulasikan menggunakan OPNET IT Guru dan diatur untuk menjalankan penelusuran web, email, streaming audio, dan File Transfer Protocol (FTP). Hasil yang diperoleh menunjukkan waktu respons halaman website yang signifikan, keterlambatan akses media dan throughput yang lebih tinggi (Zubairu, 2013).

Pada penelitian yang dilakukan oleh Wijaya (2014) melakukan analisis kinerja perbandingan QoS WDS dan Non WDS dengan menggunakan pengukuran parameter QoS berupa delay, packet loss, throughput, dan jitter, dengan menggunakan aplikasi Jperf untuk mendapatkan data throughput, delay/latency, packet loss dan aplikasi iperf untuk mendapatkan data jitter (Wijaya, 2014).

Kemudian pada penelitian yang dilakukan oleh Nurprasetyo dan Kusnawi (2015) yang meneliti tentang kinerja WDS dengan melakukan pengujian terhadap jaringan yang belum WDS dan yang sudah WDS, proses pengujian menggunakan beberapa aplikasi untuk memudahkan dalam pengukuran kinerja WDS (Nurprasetyo \& Kusnawi, 2015).

Sedangkan pada penelitian Wirnaningrat dan Syafrizal (2016) melakukan penelitian tentang Wireless Distribution System (WDS) berdasarkan Quality of Service (QOS) dengan parameter thoughput, delay, packet loss, dan jitter di Kedai Oak dengan hasil bahwa implementasi WDS berjalan dengan sangat baik dan telah memenuhi standar yang 
ditentukan oleh QoS, sehingga pada pelanggan tidak khawatir terjadi packet loss ketika pelanggan berpindah tempat dari depan ke belakang Kedai Oak (Wirnaningrat \& Syafrizal, 2016).

Pada penelitian yang dilakukan oleh Hidayatullah dan Kusnawi (2016) melakukan penelitian tentang analisis perbandingan QoS firmware original TLWR841ND dengan firmware OpenWRT berbasis Open Source, menunjukkan bahwa throughput yang didapat dalam pengujian tidak ada berbedaan bahkan hampir sama. Nilai jitter dan packet loss pada kategori bagus sedangkan nilai delay pada kategori sangat bagus (Hidayatullah \& Kusnawi, 2016).

Selanjutnya pada penelitian Sholikhin et al. (2017) yang melakukan penelitian tentang penerapan wireless distribution system (WDS) mesh untuk optimasi coverage area WIFI Universitas Muhammadiyah Jember menunjukkan WDS mampu memenuhi cakupan area wifi sebesar 13 hektar di Universitas Muhammadiyah Jember (Sholikhin, Warisaji, \& Cahyanto, 2017).

\section{Analisis dan Perancangan}

\section{II.1 Analisis Sistem yang Sedang Berjalan}

Jaringan wireless di Universitas Widyatama pada saat ini masih mempergunakan kabel Unshielded Twisted Pair (UTP) sebagai backbone dari semua access point yang terpasang. Dapat dilihat pada gambar 1 bahwa semua access point masih menggunakan kabel UTP sebagai backbone.

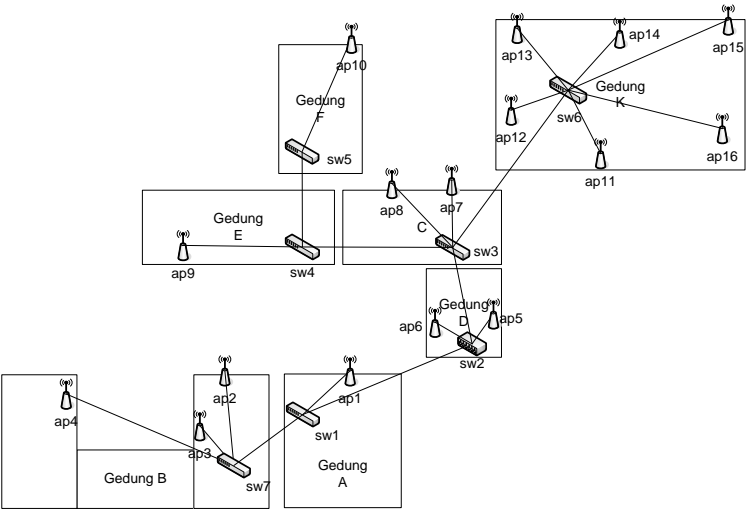

Gambar 1. Topologi Jaringan Wireless yang Berjalan
Kebutuhan perangkat keras dapat dilihat pada tabel 1 berikut.

Tabel 1. Kebutuhan Perangkat Keras

\begin{tabular}{|c|l|c|l|}
\hline No & Nama & Qty & \multicolumn{1}{|c|}{ Keterangan } \\
\hline \multirow{2}{*}{1} & \multirow{2}{*}{$\begin{array}{l}\text { Access } \\
\text { Point }\end{array}$} & 2 & $\begin{array}{l}\text { UBNT Rocket M2 + Antena } \\
\text { Omni }\end{array}$ \\
\cline { 3 - 4 } & Switch & 1 & $\begin{array}{l}\text { Rocket M2 + Antena Sectoral } \\
120^{0}\end{array}$ \\
\cline { 3 - 4 } 3 & Kabel UTP & 28 & UBNT PicoStation M2 \\
\hline 2 & 2 & $\begin{array}{l}\text { Kabel } \text { backbone access point } \\
\text { (AP) basestation dan untuk } \\
\text { kabel Power Over Ethernet } \\
\text { (POE) semua AP }\end{array}$ \\
\hline
\end{tabular}

Penggunaan Access Point (AP) bermerek UBNT, dikarenakan mendukung jaringan wireless dengan WDS dan dalam melakukan konfigurasi AP cukup user friendly.

\section{II.3 Desain Jaringan Wireless Mengunakan WDS yang Diusulkan}

Desain topologi jaringan wireless menggunakan Wireless Distribution System (WDS) dapat dilihat pada gambar 2. Desain jaringan wireless menggunakan WDS yang diusulkan sudah memanfaatkan jalur wireless sebagai backbone dari access point.

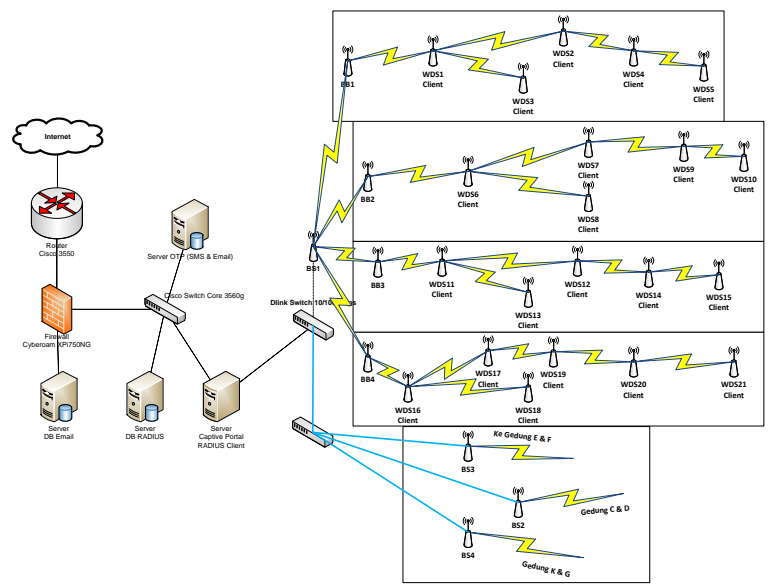

Gambar 2. Desain Jaringan Wireless yang Diusulkan

Penggunaan jalur wireless sebagai backbone dari access point memiliki beberapa kelebihan, diantaranya:

\section{II.2 Analisis Kebutuhan Sistem}


1) Jaringan wireless dengan WDS mendukung wireless roaming. Wireless roaming merupakan keadaan dimana suatu perangkat wireless dapat berpindah dari satu access point (AP) ke access point (AP) yang lain dalam subnet yang sama. WDS memungkin hubungan beberapa AP dalam satu perangkat jaringan wireless (Husni \& Zaen, 2018).

2) Jaringan wireless dengan WDS merupakan teknologi baru yang memiliki fleksibilitas yang tinggi (Sulistyo, Bayu, \& Sathibi, 2012).

3) Jaringan wireless dengan WDS dapat menghubungkan semua access point menjadi satu kesatuan serta memiliki mobilitas dan reliabilitas tinggi (Sejati, Widiasari, \& Wellem, 2012).

4) Jaringan wireless dengan WDS adalah suatu cara memperluas jaringan wireless, dimana dengan WDS sangat memungkinkan membangun infrastruktur jaringan wireless tanpa harus membangun backbone kabel jaringan sebagai interkoneksi antar Access Point (AP), dimana tidak memungkinkan untuk memasang jaringan kabel, karena lebih mahal, terbatas, atau secara fisik memang tidak memungkinkan untuk membuat jaringan kabel (Fawzian, Munadi, \& Sanjoyo, 2018).

\section{II.4 Skenario Pengujian Quality of Service}

Skenario pengujian Quality of Service (QoS) jaringan wireless menggunakan Wireless Distribution System (WDS) dengan menggunakan aplikasi Axence NetTools, dengan parameter yang akan di uji throughput, delay, packet loss, dan jitter. Pengujian dilakukan pada saat pagi hari, siang, dan sore dengan rentang waktu selama 1 jam.

\section{II.5 Hasil Konfigurasi Access Point}

Hasil penelitian ini diperoleh dengan teknik observasi dan wawancara yang dikaitkan kepada beberapa unsur atau identifikasi masalah. Supaya penelitian ini lebih terarah dan akurat, maka diperlukan informasi-informasi tambahan dengan melakukan teknik studi literatur yang dapat dijadikan rujukan dalam penelitian ini. Hasil penelitian desain jaringan wireless menggunakan Wireless Distribution System (WDS) berdasarkan Quality of Service (QoS) memiliki langkah-langkah sebagai berikut:

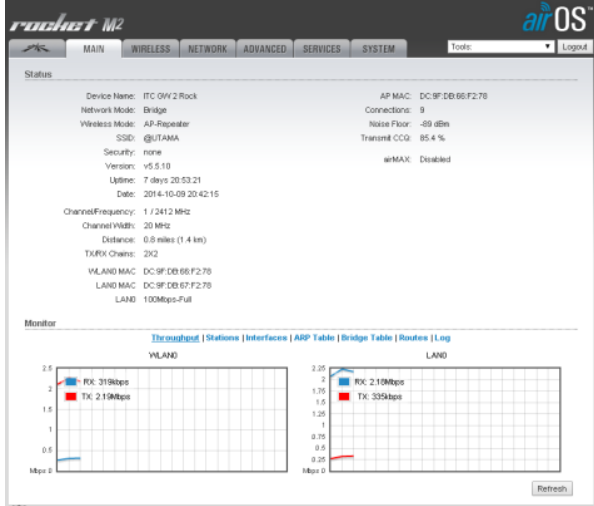

Gambar 3. Main Menu AP UBNT

1) Langkah pertama dalam melakukan konfigurasi access point adalah dengan membuka web browser, kemudian pada address bar ketik IP default 192.168.1.20, kemudian login menggunakan akun default (username: ubnt dan password: ubnt) setelah berhasil login, maka akan akan terlihat menu main AirOs Ubiquiti. Pada gambar 3 menampilkan informasi konfigurasi WDS pada access point.

2) Langkah kedua klik menu wireless dapat lihat pada gambar 4, isi dari tab menu wireless, yaitu:

a. Wireless Mode dengan 3 pilihan mode, Access Point, Station dan AP-Repeater, maka dengan demikian untuk mendukung mode Wireless Distribution System (WDS) maka pilih Wireless Mode: AP-Repeater.

b. SSID merupakan singkatan dari Service Set Identifier. Untuk SSID diisi dengan @UTAMA.

c. WDS Peers merupakan Media Access Control (MAC) Address dari client WDS yang saling terhubung.

d. Country Code: Indonesia

e. IEEE $802.11: B / G / N$ Mixed

f. Channel Width: $20 \mathrm{Mhz}$

g. Channel Shifting: Disable

h. Frequency, MHZ: 2412 (1)

i. Output power: $28 \mathrm{dbm}$ 


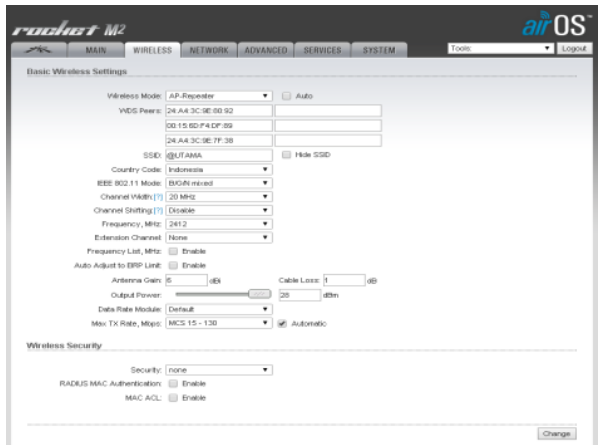

Gambar 4. Menu Konfigurasi Wireless AP UBNT

3) Langkah ketiga klik tab menu network untuk melakukan konfigurasi IP address dari access point, seperti dapat dilihat pada gambar 5, konfigurasi meliputi:

a. Network Mode: Bridge

b. Configuration mode: Simple

c. Management IP Address: Static

d. IP Address: 172.16.0.1 (Class B)

e. Netmask: 255.255.0.0

f. Gateway IP: 172.16.1.1

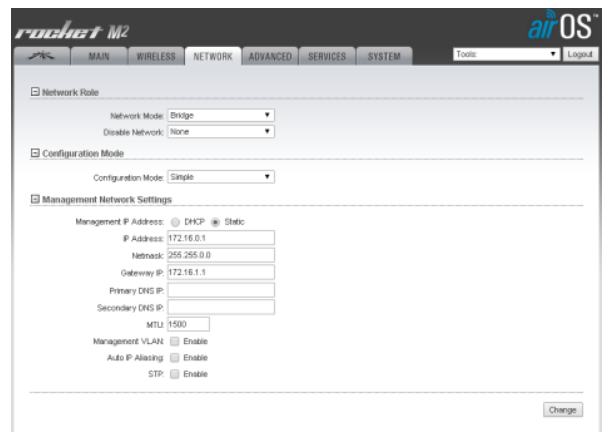

Gambar 5. Menu Konfigurasi Network AP UBNT

4) Langkah terakhir klik menu advanced, seperti terlihat pada gambar 6. Konfigurasi yang perlu diterapkan pada menu advanced, yaitu:
a. RTS Threshold: Off
b. Distance: Auto Adjust
c. Aggregation: Enable, 32 Frame, dan $50 \mathrm{kB}$
d. Multicast Data: Allow All
e. Multicast Enhancement: Enable
f. Installer ERP Control: Enable

\section{g. Extra Reporting: Enable \\ h. Client Isolation: Disable}

Demikian langkah-langkah dalam melakukan konfigurasi mode WDS pada access point UBNT/Ubiquiti yang digunakan pada penelitian ini, langkah-langkah konfigurasi baik disisi basestation maupun access point station dapat dikatakan sama, karena pada penelitian ini menggunakan perangkat dengan produsen yang sejenis yaitu UBNT dengan aplikasi AirOs yang berbasis web.

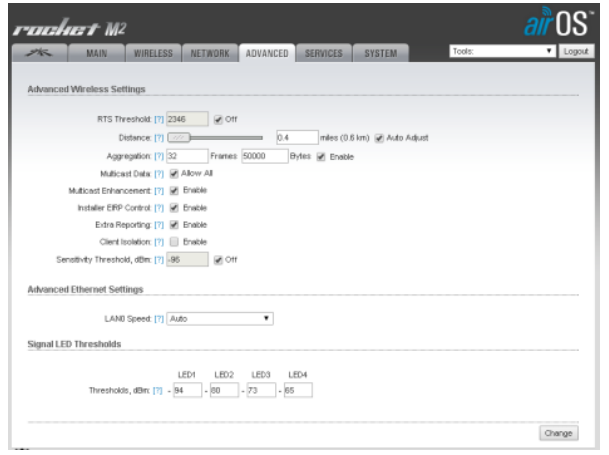

Gambar 6. Menu Konfigurasi Advanced AP UBNT

\section{II.6 Hasil Pengujian Quality of Service (QoS) WDS}

Pengujian Quality of Service (QoS) pada Wireless Distribution System (WDS) menggunakan aplikasi Axence Nettools untuk mendapatkan hasil data parameter throughput, jitter, delay atau latency dan packet loss.

\section{1) Hasil Pengujian Throughput}

Throughput merupakan kecepatan (rate) transfer data yang efektif, yang dapat diukur dalam bit per second (bps), yang merupakan jumlah total kedatangan paket yang sukses yang diamati pada tujuan selama interval waktu tertentu yang dibagi oleh durasi interval waktu tersebut. Pengukuran throughput mengacu pada standar Telecommunications and Internet Protocol Harmonization Over Networks (TIPHON) yang mengkategorikan throughput seperti pada tabel 2 berikut.

Tabel 2. Kategori Throughput

\begin{tabular}{|l|c|c|}
\hline $\begin{array}{c}\text { Kategori } \\
\text { Throughput }\end{array}$ & Throughput & Indeks \\
\hline Sangat Bagus & $100 \%$ & 4 \\
\hline Bagus & $75 \%$ & 3 \\
\hline Sedang & $50 \%$ & 2 \\
\hline Jelek & $<25 \%$ & 1 \\
\hline
\end{tabular}


Berdasarkan tabel 3 didapatkan nilai rata-rata throughput dengan presentase sebesar 90\%, maka merujuk pada kategori standar TIPHON jaringan wireless dengan WDS dapat dikategorikan throughput-nya BAGUS dengan indeks 3.

Tabel 3. Hasil Pengujian Throughput

\begin{tabular}{|c|c|c|c|c|c|c|}
\hline T & $\begin{array}{c}\text { Min } \\
(\text { Kbps) }\end{array}$ & $\begin{array}{c}\text { Max } \\
(\text { Kbps) }\end{array}$ & $\begin{array}{c}\text { Average } \\
(\text { Kbps) }\end{array}$ & $\begin{array}{c}\text { Packet } \\
\text { Sent }\end{array}$ & \multicolumn{2}{|c|}{$\begin{array}{c}\text { Packet } \\
\text { Received }\end{array}$} \\
\hline 1 & 163 & 699 & 411 & 40 & 38 & $93 \%$ \\
\hline 2 & 101 & 739 & 304 & 52 & 48 & $90 \%$ \\
\hline 3 & 148 & 683 & 329 & 42 & 40 & $93 \%$ \\
\hline 4 & 102 & 667 & 246 & 45 & 38 & $79 \%$ \\
\hline 5 & 115 & 615 & 277 & 42 & 40 & $93 \%$ \\
\hline $\begin{array}{c}\text { Rata- } \\
\text { rata }\end{array}$ & 125,8 & 680,6 & 313,4 & 44,2 & 40,8 & $90 \%$ \\
\hline
\end{tabular}

\section{2) Hasil Pengujian Delay dan Packet Loss}

Delay merupakan waktu yang diperlukan suatu data untuk menempuh jarak dari asal menuju ke tujuan. Delay dipengaruhi oleh jarak dan waktu proses yang lama.

Tabel 4. Kategori Delay

\begin{tabular}{|l|c|c|}
\hline Kategori Latency & Besar Delay & Indeks \\
\hline Sangat Bagus & $<150 \mathrm{~ms}$ & 4 \\
\hline Bagus & $150 \mathrm{~s} / \mathrm{d} 300 \mathrm{~ms}$ & 3 \\
\hline Sedang & $300 \mathrm{~s} / \mathrm{d} 450 \mathrm{~ms}$ & 2 \\
\hline Jelek & $>450 \mathrm{~ms}$ & 1 \\
\hline
\end{tabular}

Tabel 5. Kategori Packet Loss

\begin{tabular}{|l|c|c|}
\hline $\begin{array}{c}\text { Kategori } \\
\text { Degradasi }\end{array}$ & Packet Loss & Indeks \\
\hline Sangat Bagus & $0 \%$ & 4 \\
\hline Bagus & $3 \%$ & 3 \\
\hline Sedang & $15 \%$ & 2 \\
\hline Jelek & $25 \%$ & 1 \\
\hline
\end{tabular}

Berdasarkan tabel 6 didapatkan nilai rata-rata delay sebesar 107.8, maka merujuk pada kategori standar TIPHON jaringan wireless dengan Wireless Distribution System (WDS) dapat dikategorikan SANGAT BAGUS dengan indeks 4, sedangkan nilai rata-rata packet loss dengan presentase $2 \%$, merujuk pada kategori standar TIPHON jaringan wireless dengan WDS dapat dikategorikan BAGUS dengan indeks 3 .
Tabel 6. Hasil Pengujian Delay dan Packet Loss

\begin{tabular}{|c|c|c|c|c|c|c|c|c|}
\hline W & Min & Max & $\begin{array}{c}\text { Rata- } \\
\text { rata } \\
(\mathbf{m s})\end{array}$ & $\begin{array}{c}\text { Packet } \\
\text { Sent }\end{array}$ & \multicolumn{2}{|c|}{$\begin{array}{c}\text { Packet } \\
\text { Received }\end{array}$} & \multicolumn{2}{|c|}{ Packet } \\
Loss
\end{tabular}

\section{3) Hasil Pengujian Jitter}

Jitter lazimnya disebut variasi delay atau variasi waktu kedatangan paket, berhubungan erat dengan latency, yang menunjukkan banyaknya variasi delay pada transmisi data di jaringan. Delay antrian pada router dan switch dapat menyebabkan jitter.

\begin{tabular}{|l|c|c|}
\hline $\begin{array}{c}\text { Kategori } \\
\text { Degradasi }\end{array}$ & Peak Jitter & Indeks \\
\hline Sangat Bagus & $0 \mathrm{~ms}$ & 4 \\
\hline Bagus & $1 \mathrm{~s} / \mathrm{d} 75 \mathrm{~ms}$ & 3 \\
\hline Sedang & $75 \mathrm{~s} / \mathrm{d} 125 \mathrm{~ms}$ & 2 \\
\hline Jelek & $125 \mathrm{~s} / \mathrm{d} 225 \mathrm{~ms}$ & 1 \\
\hline
\end{tabular}

Hasil pengujian diperoleh nilai jitter yang bervariasi dengan nilai rata-rata jitter pada tabel 7 sebesar $1.71 \mathrm{~ms}$, sehingga menurut TIPHON dapat dikategorikan nilai jitter jaringan wireless dengan WDS dapat dikategorikan BAGUS dengan indeks 3.

Tabel 7. Hasil Pengujian Jitter

\begin{tabular}{|c|c|c|c|c|}
\hline $\begin{array}{c}\text { Interval } \\
(\mathbf{s})\end{array}$ & $\begin{array}{c}\text { Transfer } \\
(\mathbf{M B p s})\end{array}$ & $\begin{array}{c}\text { Bandwidth } \\
(\mathbf{M b p s})\end{array}$ & $\begin{array}{c}\text { Jitter } \\
(\mathbf{m s})\end{array}$ & Kategori \\
\hline $0,0-1,0$ & 2,40 & 11,20 & 1,26 & Bagus \\
\hline $1,0-2,0$ & 2,39 & 11,20 & 1,26 & Bagus \\
\hline $2,0-3,0$ & 2,39 & 11,20 & 1,32 & Bagus \\
\hline $3,0-4,0$ & 2,39 & 11,15 & 1,69 & Bagus \\
\hline $4,0-0,5$ & 2,39 & 11,16 & 1,75 & Bagus \\
\hline $5,0-6,0$ & 2,39 & 11,20 & 1,77 & Bagus \\
\hline $6,0-7,0$ & 2,39 & 11,20 & 1,90 & Bagus \\
\hline $7,0-8,0$ & 2,39 & 11,16 & 1,92 & Bagus \\
\hline $8,0-9,0$ & 2,39 & 11,20 & 1,97 & Bagus \\
\hline $9,0-10,0$ & 2,39 & 11,17 & 1,97 & Bagus \\
\hline $0,0-10,0$ & 13,10 & 11,19 & 1,97 & Bagus \\
\hline Rata-rata & 3,36 & 11,18 & 1,71 & Bagus \\
\hline
\end{tabular}




\section{KESIMPULAN DAN SARAN}

Berdasarkan penelitian yang telah dilakukan, maka diperoleh kesimpulan sebagai berikut:

Desain jaringan wireless dengan Wireless Distribution System (WDS) memiliki tingkat fleksibilitas yang lebih baik daripada backbone yang menggunakan kabel Unshielded Twisted Pair (UTP). Hasil pengujian menunjukkan bahwa throughput, delay, packet loss, dan jitter menunjukkan hasil yang bagus. Hasil pengujian throughput didapatkan nilai rata-rata throughput dengan presentase sebesar 90\%, dapat dikategorikan BAGUS dengan indeks 3, sedangkan hasil pengujian delay didapatkan nilai ratarata sebesar107,8 dapat dikategorikan SANGAT BAGUS dengan indeks 4, kemudian nilai rata-rata packet loss dengan presentase 2\%, dapat dikategorikan BAGUS dengan indeks 3 , dan hasil pengujian jitter diperoleh nilai yang bervariasi dengan nilai rata-rata jitter sebesar $1,71 \mathrm{~ms}$, dapat dikategorikan BAGUS dengan indeks 3.

\section{REFERENSI}

Fawzian, R., Munadi, R., \& Sanjoyo, D. D. (2018). Implementasi dan Analisis Performansi Wireless Distribution System pada Layanan Video Conference. E-Proceeding of Engineering, 5(1), 555-563.

Hidayatullah, M. S., \& Kusnawi. (2016). Analisis Perbandingan Quality of Service ( QoS ) Firmware Original TL-MR3020 Dengan Firmware OpenWRT. Jurnal Ilmiah Teknologi Informasi Terapan (Jitter), II(2), 150-156.

Husni, F., \& Zaen, M. T. A. (2018). Implementasi Internal Wireless Roaming Menggunakan Mikrotik Wireless Distribution System (WDS). Jurnal Informatika \& Rekayasa Elektronika (JIRE), 1(1), 38-43.

Nurprasetyo, S., \& Kusnawi. (2015). Analisis Kinerja WDS (Wireless Distribution System) Dengan Menggunakan TL-WR841ND Sebagai Wireless Repeater. STMIK AMIKOM Yogyakarta, 16(2), 39-55.

https://doi.org/10.1377/hlthaff.2013.0625

Rusdan, M. (2019). Pengujian Jaringan Nirkabel STT Bandung Menggunakan Quality of Service (QoS). Jurnal Ilmiah TEDC, 13(1), 1-5.
Rusdan, M., \& Sabar, M. (2019). Pengembangan Jaringan Wireless Menggunakan User Authentication Berbasis Radius Dalam Industri 4.0. Infotech Journal, 5(1), 44-52. Retrieved from

https://www.jurnal.unma.ac.id/index.php/infote ch/article/view/1449

Sejati, F. A. K., Widiasari, I. R., \& Wellem, T. (2012). Perancangan dan Analisis External Wireless Roaming Pada Jaringan Hotspot Menggunakan Dua Jaringan Mobile Broadband. Seminar Nasional Teknologi Informasi \& Komunikasi Terapan 2012 (Semantik 2012), 2012(Semantik), 1-8.

Sholikhin, A. R., Warisaji, T. T., \& Cahyanto, T. A. (2017). Penerapan Wireless Distribution System ( WDS ) Mesh Untuk Optimasi Coverage Area Wifi Universitas Muhammadiyah Jember. Jurnal Universitas Muhammadiyah Jember, 17.

Sulistyo, W., Bayu, T. I., \& Sathibi, A. (2012). Implementasi Dan Analisis Penggunaan DDWRT Firmware Untuk Membangun Jaringan Wireless Distribution System Pada Jaringan Hotspot ( Studi Kasus : FTI UKSW ). Seminar Nasional Aplikasi Teknologi Informasi 2012 (SNATI 2012), 2012(Wireless Distribution System), 96-105.

Wijaya, C. (2014). Perancangan Dan Analisa Wireless Distribution System (WDS) Berbasis OpenWRT Menggunakan Tl-MR3020. STMIK PalComTech Palembang, 1-15.

Wirnaningrat, T. W., \& Syafrizal, M. (2016). Analisis dan Perancangan Teknologi WDS (Wireless Distribution System) Berdasarkan QoS (Quality of Service) pada Kedai Oak. STMIK AMIKOM Yogyakarta, 53(9), 1689-1699. https://doi.org/10.1017/CBO9781107415324.00 4

Zubairu, B. (2013). Designing of Wireless Distribution System Network (WDSN) Model. Academic Journal of Interdisciplinary Studies, 2(7), 97-102. https://doi.org/10.5901/ajis.2013.v2n7p97 